\title{
Hypocretin/Orexin Overexpression Induces An Insomnia-Like Phenotype in Zebrafish
}

\author{
David A. Prober, ${ }^{1}$ Jason Rihel, ${ }^{1}$ Anthony A. Onah, ${ }^{1}$ Rou-Jia Sung, ${ }^{1}$ and Alexander F. Schier ${ }^{1,2,3,4,5}$ \\ ${ }^{1}$ Department of Molecular and Cellular Biology, ${ }^{2}$ Division of Sleep Medicine, ${ }^{3}$ Center for Brain Science, ${ }^{4}$ Harvard Stem Cell Institute, and ${ }^{5}$ Broad Institute, \\ Harvard University, Cambridge, Massachusetts 02138
}

As many as $10 \%$ of humans suffer chronic sleep disturbances, yet the genetic mechanisms that regulate sleep remain essentially unknown. It is therefore crucial to develop simple and cost-effective vertebrate models to study the genetic regulation of sleep. The best characterized mammalian sleep/wake regulator is hypocretin/orexin (Hcrt), whose loss results in the sleep disorder narcolepsy and that has also been implicated in feeding behavior, energy homeostasis, thermoregulation, reward seeking, addiction, and maternal behavior. Here we report that the expression pattern and axonal projections of embryonic and larval zebrafish Hcrt neurons are strikingly similar to those in mammals. We show that zebrafish larvae exhibit robust locomotive sleep/wake behaviors as early as the fifth day of development and that Hcrt overexpression promotes and consolidates wakefulness and inhibits rest. Similar to humans with insomnia, Hcrtoverexpressing larvae are hyperaroused and have dramatically reduced abilities to initiate and maintain rest at night. Remarkably, Hcrt function is modulated by but does not require normal circadian oscillations in locomotor activity. Our zebrafish model of Hcrt overexpression indicates that the ancestral function of $\mathrm{Hcrt}$ is to promote locomotion and inhibit rest and will facilitate the discovery of neural circuits, genes, and drugs that regulate Hcrt function and sleep.

Key words: hypocretin; orexin; sleep; insomnia; circadian rhythm; zebrafish

\section{Introduction}

Sleep remains a fundamental mystery of biology. It is unclear how sleep and wakefulness are regulated, and the function of sleep remains controversial (Hendricks et al., 2000a; Greenspan et al., 2001; Hobson, 2005; Saper et al., 2005; Siegel, 2005). The genetic mechanisms that regulate sleep are of great medical interest, because $>10 \%$ of Americans suffer chronic sleep disorders (Colten and Altevog, 2006). Insomnia, defined as an impaired ability to initiate or maintain sleep (American Academy of Sleep Medicine, 2001), accounts for $\sim 50 \%$ of sleep-related complaints (Colten and Altevog, 2006).

The identification of defective hypocretin/orexin (Hcrt) signaling as a cause of mammalian sleep disorders highlighted the power of genetic approaches to sleep research. Dogs and mice that lack either the neuropeptide Hcrt or its G-protein-coupled receptors have symptoms of narcolepsy, a syndrome characterized by excessive daytime sleepiness, fragmented sleep/wake states, and sudden loss of muscle tone during waking (cataplexy)

Received 0ct. 4, 2006; revised Nov. 9, 2006; accepted Nov. 13, 2006.

This work was supported by grants from the National Institutes of Health and the McKnight Endowment Fund for Neuroscience (A.F.S.). D.A.P. was supported by a fellowship from the Helen Hay Whitney Foundation. J.R. is a Bristol-Myers Squibb Fellow of the Life Sciences Research Foundation. We thank Wolfgang Driever, Su Guo, Shin-Ichi Higashijima, and Steve Wilson for providing in situ probes, Steven Zimmerman for technical assistance, Amir Karger for assistance with data analysis, Patrick Mabray and Irina Zhdanova for advice on behavioral assays, and Sebastian Kraves for comments on this manuscript.

Correspondence should be addressed to David A. Prober or Alexander F. Schier, Department of Molecular and Cellular Biology, Harvard University, 16 Divinity Avenue, Cambridge, MA 02138. E-mail: schier@mcb.harvard.edu, prober@fas.harvard.edu.

D0I:10.1523/JNEUROSCI.4332-06.2006

Copyright $\odot 2006$ Society for Neuroscience $\quad$ 0270-6474/06/2613400-11\$15.00/0
(Chemelli et al., 1999; Lin et al., 1999; Hara et al., 2001; Willie et al., 2003; Mochizuki et al., 2004; Siegel, 2004). Conversely, direct injection of Hcrt protein into the brain increases locomotor activity and decreases sleep for a few hours (Sakurai et al., 1998; Hagan et al., 1999; Ida et al., 1999; Yamanaka et al., 1999, 2002; Bourgin et al., 2000; John et al., 2000; Nakamura et al., 2000; Piper et al., 2000; Huang et al., 2001; Jones et al., 2001; Espana et al., 2002; Fujiki et al., 2003; Mieda et al., 2004; Nakamachi et al., 2006). These studies led to the hypothesis that Hcrt signaling maintains wakefulness. However, the long-term effects of increased Hcrt signaling on behavior remain unknown but will greatly impact the therapeutic potential of drugs that stimulate Hcrt signaling (Zeitzer et al., 2006).

Here we introduce the zebrafish as a model system to analyze the ancestral roles of Hcrt signaling and to determine the effects of long-term Hcrt overexpression on behavior. Previous studies demonstrated that late-larval zebrafish have sleep-like states similar to mammals and Drosophila (Hendricks et al., 2000b; Shaw et al., 2000; Zhdanova et al., 2001; Saper et al., 2005; Siegel, 2005). Assays for locomotor activity revealed that zebrafish larvae are less active and exhibit increased arousal thresholds to a mechanical stimulus at night (Zhdanova et al., 2001). It has also been shown that the single zebrafish Hcrt ortholog is expressed in neurons in the posterior hypothalamus (Kaslin et al., 2004; Faraco et al., 2006) that project to monoaminergic and cholinergic nuclei in adult zebrafish (Kaslin et al., 2004), as in mammals (Peyron et al., 1998; Chemelli et al., 1999; Date et al., 1999; Hagan et al., 1999; Horvath et al., 1999; Nambu et al., 1999; Nakamura et al., 2000). These studies raised the questions of whether Hcrt regulates sleep/wake states in zebrafish and whether the Hcrt cir- 

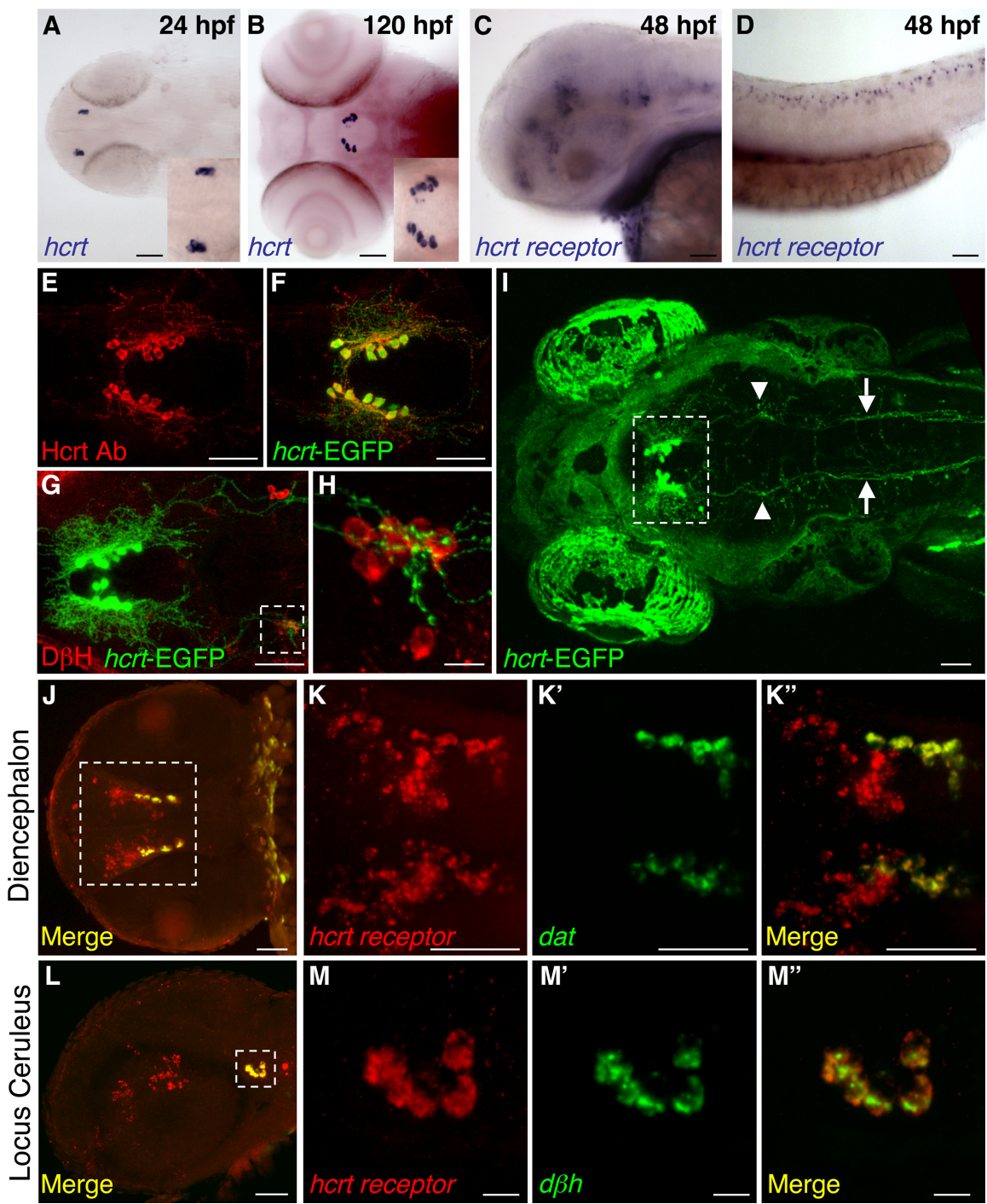

Figure 1. Hcrt and Hcrt receptor expression during embryonic and larval stages. $\boldsymbol{A}, \boldsymbol{B}, \mathrm{h}$ crt $\mathrm{mRNA}$ is expressed in two bilaterally symmetric clusters of neurons in the posterior hypothalamus that each contains two to four neurons at $24 \mathrm{hpf}(\boldsymbol{A}$, enlarged in inset) and 7-10 neurons at $120 \mathrm{hpf}$ ( $\boldsymbol{B}$, enlarged in inset). At $48 \mathrm{hpf}$, $h$ crt receptor mRNA is expressed in discrete clusters of neurons in the forebrain, midbrain, and hindbrain $(\boldsymbol{C})$ and in a row of neurons along the spinal cord $(\boldsymbol{D})$. An Hcrt1 peptide-specific antibody (Ab) $(\boldsymbol{E}, \boldsymbol{F})$ and $h c r t-E G F P$ transgenic fish $(\boldsymbol{F}-\boldsymbol{I})$ label Hcrt neurons and reveal extensive projections within the diencephalon $(\boldsymbol{E}, \boldsymbol{F}, \boldsymbol{G}, \boldsymbol{I})$, sparse projections to the forebrain $(\boldsymbol{E}, \boldsymbol{F})$, dense projections to the locus ceruleus [labeled with a dopamine $\beta$ hydroxylase (D $\beta H)$ antibody (G,H; arrowheads in $I$ )], and projections down the spinal cord (arrows in $I$ ) at $120 \mathrm{hpf}$. EGFP-expressing Hcrt neurons are boxed in I to distinguish them from autofluorescence in the eyes and skin. The hcrt receptor is expressed in diencephalic dopaminergic neurons that express the dopamine transporter (dat) $(\boldsymbol{J}, \boldsymbol{K})$ and in noradrenergic neurons of the locus ceruleus that express dopamine $\beta$ hydroxylase $(d \beta h)(\boldsymbol{L}, \boldsymbol{M})$. Boxed regions in $\boldsymbol{G}, \boldsymbol{J}$, and $\boldsymbol{L}$ are shown at higher magnification in $\boldsymbol{H}, \boldsymbol{K}$, and $\boldsymbol{M}$. $\boldsymbol{J}$ is provided for orientation but was imaged from a different embryo than shown in $\boldsymbol{K}$. Anterior is to the left. $\boldsymbol{A}, \boldsymbol{B}, \boldsymbol{I} \boldsymbol{- K}$ are dorsal views, $\boldsymbol{E}-\boldsymbol{H}$ are ventral views, and $\boldsymbol{C}, \boldsymbol{D}, \boldsymbol{L}, \boldsymbol{M}$ are side views. Scale bars: $\boldsymbol{A}-\mathbf{G}, \boldsymbol{I}-\boldsymbol{L}, 50 \mu \mathrm{m} ; \boldsymbol{H}, \boldsymbol{M}, 10 \mu \mathrm{m}$.

cuit is functional during larval stages. To address these questions, we generated an inducible, long-lasting genetic model of Hcrt overexpression in zebrafish larvae and developed highthroughput locomotor activity and arousal assays to study sleep/ wake behaviors.

\section{Materials and Methods}

Isolation of zebrafish hcrt receptor

Full-length hcrt receptor (HcrtR) cDNA was amplified by performing reverse transcription-PCR with Superscript II (Invitrogen, Carlsbad, CA) using primers based on sequence from $5^{\prime}$ rapid amplification of cDNA ends (RACE) (FirstChoice RLM-RACE; Ambion, Austin, TX) and Ensembl exon prediction. The hort receptor cDNA sequence has been deposited in GenBank under accession number EF122429.
In situ hybridization

Single in situ hybridizations were performed using standard protocols and developed using nitroblue-tetrazolium-chloride/5-bromo-4-chlorindolyl-phosphate (Roche, Indianapolis, IN). Double-fluorescent in situ hybridizations were performed using DIG- and 2,4-dinitrophenol (DNP)-labeled riboprobes and the TSA Plus DNP System (PerkinElmer, Wellesley, MA).

\section{Immunofluorescence}

Samples were fixed in $4 \%$ paraformaldehyde/ PBS overnight at $4^{\circ} \mathrm{C}$ and then washed with $0.25 \%$ Triton X-100/PBS (PBTx). Brains were manually dissected and blocked for at least $1 \mathrm{~h}$ in $2 \%$ sheep serum $/ 2 \%$ DMSO/PBTx. Antibody incubations were performed in block solution overnight at $4^{\circ} \mathrm{C}$. Primary antibodies were rabbit anti-orexin A (AB3704, 1:500; Chemicon, Temecula, CA), rabbit anti-dopamine $\beta$ hydroxylase (AB1585, 1:100; Chemicon), mouse anti-tyrosine hydroxylase (MAB318, 1:100; Chemicon), rabbit anti-histamine (AB5885, 1:1000; Chemicon), and rabbit anti-serotonin (S5545, 1:1000; Sigma, St. Louis, MO). Kaslin et al. used a blocking Hcrt peptide to demonstrate that the rabbit anti-orexin A antibody specifically labels hypothalamic Hcrt neurons in adult zebrafish (Kaslin et al., 2004). Alexa 594conjugated secondary antibodies (1:500; Invitrogen) were used. Samples were mounted in 100\% glycerol and imaged on a Zeiss (Oberkochen, Germany) Pascal confocal microscope.

\section{Generation of transgenic fish}

hort-enhanced green fluorescent protein. A 2.4 $\mathrm{kb}$ fragment of Fugu rubripes genomic DNA containing $2 \mathrm{~kb}$ of upstream sequence, the putative hort first exon, intron, and the beginning of the second exon (Ensembl Fugu Assembly 4.0; scaffold_15 nucleotides 14509101453276), was amplified using the Expand High Fidelity kit (Roche). This sequence was subcloned upstream of enhanced green fluorescent protein (EGFP) and flanked by adenoassociated viral inverted terminal repeat elements (Hsiao et al., 2001) and sites recognized by the homing endonuclease I-SceI (Thermes et al., 2002). For transient expression experiments, $\sim 20$ pg of plasmid DNA was injected into embryos at the one-cell stage. Live hortEGFP-expressing larvae were mounted in $0.8 \%$ low-melting agarose and imaged on a Zeiss LSM510 confocal microscope.

Heat-shock promoter driven Hcrt. Full-length zebrafish hort cDNA was isolated using $5^{\prime}$ and $3^{\prime}$ RACE (FirstChoice RLM-RACE; Ambion) and cloned downstream of the zebrafish $h s p 70 c$ promoter (Halloran et al., 2000) in a vector containing flanking ISceI sites. Stable transgenic fish were generated by injecting plasmids with ISceI enzyme into the cytoplasm of embryos at the one-cell stage.

\section{Behavioral analysis}

Locomotor activity analysis. Larvae were raised on a $14 / 10 \mathrm{~h}$ light/dark (LD) cycle at $28.5^{\circ} \mathrm{C}$. On the fourth day of development, single larva were placed in each of 80 wells of a 96-well plate (7701-1651; Whatman, Clifton, NJ), which allowed simultaneous tracking of each larva and prevented the larvae from interfering with the activity of each other. Locomotor activity was monitored for several days using an automated video-tracking system (Videotrack; ViewPoint Life Sciences, Montreal, 
Quebec, Canada) with a Dinion one-third inch Monochrome camera (model LTC0385; Bosch, Fairport, NY) fitted with a fixed-angle megapixel lens (M5018-MP; Computar) and infrared filter, and the movement of each larva was recorded using Videotrack quantization mode. The 96-well plate and camera were housed inside a custommodified Zebrabox (ViewPoint Life Sciences) that was continuously illuminated with infrared lights and was illuminated with white lights from 9:00 A.M. to 11:00 P.M. The 96-well plate was housed in a chamber filled with circulating water to maintain a constant temperature of $28.5^{\circ} \mathrm{C}$. The Videotrack threshold parameters for detection were matched to visual observation of the locomotion of single larva. The Videotrack quantization parameters were set as follows: detection threshold, 40; burst (threshold for very large movement), 25; freeze (threshold for no movement), 4; bin size, $60 \mathrm{~s}$. The data were further analyzed using custom PERL software and Visual Basic Macros for Microsoft (Seattle, WA) Excel. Any 1 min bin with zero detectable movement was considered $1 \mathrm{~min}$ of rest because this duration of inactivity was correlated with an increased arousal threshold; a rest bout was defined as a continuous string of rest minutes. Sleep latency was defined as the length of time from lights out to the start of the first rest bout. An active minute was defined as a $1 \mathrm{~min}$ bin with any detectable activity. An active bout was considered any continuous stretch of $1 \mathrm{~min}$ bins with detectable movement. Heat shocks were performed by placing the 96 -well plate in a $37^{\circ} \mathrm{C}$ water bath for $1 \mathrm{~h}$. Ten independent experiments totaling 302 heatshock promoter-driven Hcrt (HS-Hcrt) and 219 wild-type (WT) larvae were analyzed. We occasionally observed that HS-Hcrt larvae were more active than WT larvae even before heat shock, presumably attributable to leakiness of the heat-shock promoter (Thummel et al., 2005). This was more often observed in experiments performed under constant lighting conditions, in which circadian oscillations do not dampen the effect of overexpressed Hcrt (see Fig. 7A) (supplemental Fig. 9A, available at www.jneurosci.org as supplemental material).

Behavioral state transition analysis. To calculate transition frequencies between inactive, low-active, and high-active states, the total number of transitions from one state to another was divided by the total number of minutes spent in that state. A low-active state was defined as any $1 \mathrm{~min}$ period with activity that lasted $1 \mathrm{~s}$ or less, whereas a high-active state was defined as any $1 \mathrm{~min}$ period with $>1 \mathrm{~s}$ of activity. Using these parameters, WT larvae in a normal LD cycle spend $\sim 30 \%$ of their time in each state.

Arousal threshold analysis. White lights were manipulated during the first and second nights after heat shock with an automated timer to precisely regulate each transition. Transitions were from full lights on to full lights off in $<1 \mathrm{~s}$. The Videotrack parameters were the same as above, except that the recorded bin size was shortened to $1 \mathrm{~s}$ to ensure that changes in locomotor behavior were precisely synchronized with lighting transitions. Response latency was defined as the interval between the light transition and the first $1 \mathrm{~s}$ bin of activity. A total of $780 \mathrm{HS}$-Hcrt and 800 WT responses were recorded in three independent experiments. The Institutional and Animal Care and Use Committee of Harvard University approved all animal experiments.

\section{Results}

\section{Hcrt neurons project to Hcrt receptor-expressing neurons} associated with arousal

To study the Hcrt circuit in zebrafish, we cloned the zebrafish Hcrt and HcrtR orthologs. We found that the zebrafish genome encodes a single HcrtR ortholog that is more related to mammalian HcrtR2 (70\%) than HcrtR1 (60\%) (supplemental Fig. 1C,D, available at www.jneurosci.org as supplemental material). We also confirmed that the single zebrafish hort gene encodes Hcrt1 and Hcrt 2 peptides that are 45 and $54 \%$ identical, respectively, to their human orthologs (supplemental Fig. $1 A, B$, available at www. jneurosci.org as supplemental material) (Faraco et al., 2006).

Using in situ hybridization, we found that the hort receptor is expressed in several discrete clusters of neurons in the telencephalon, diencephalon, and hindbrain (Fig. 1C), as well as in a row of neurons along the spinal cord (Fig. $1 D$ ). Using in situ hybridiza-
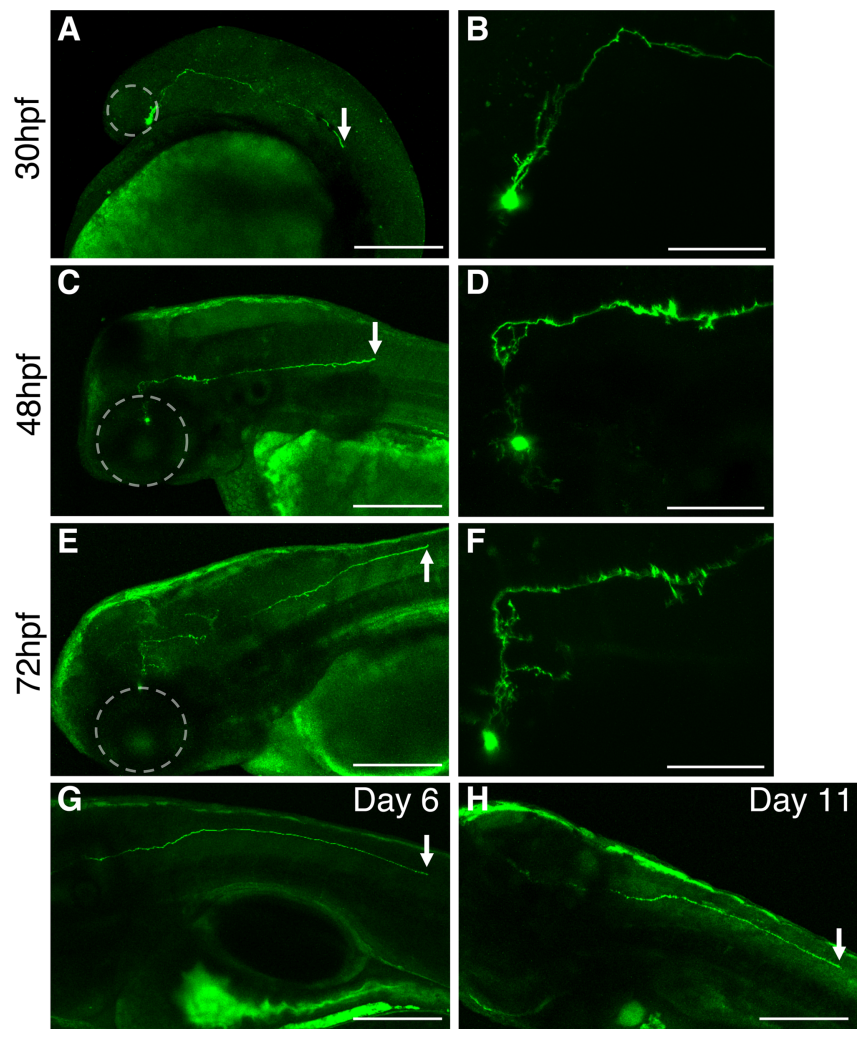

Figure 2. Time-lapse images of a developing Hort neuron. Transient injection of the hortEGFP transgene labels a single Hcrt neuron, which was repeatedly imaged up to day 11 of development. As for all Hcrt neurons that we labeled in this manner, the axon initially projects $\sim 50 \mu \mathrm{m}$ dorsally and then turns caudally and grows down the spinal cord (indicated with an arrow in $\boldsymbol{A}, \boldsymbol{C}, \boldsymbol{E}, \boldsymbol{G}, \boldsymbol{H})$. By $30 \mathrm{hpf}$, the axon has already grown $\sim 400 \mu \mathrm{m}(\boldsymbol{A})$ and eventually grows almost the entire length of the spinal cord $(\boldsymbol{A}-\boldsymbol{H}) . \boldsymbol{A}, \boldsymbol{C}, \boldsymbol{E}$ are shown at higher magnification in $\boldsymbol{B}, \boldsymbol{D}, \boldsymbol{F}$, revealing the development of dendritic and axonal arbors within the diencephalon. The eye is outlined in white for orientation. Anterior is to the left, and dorsal is up. Scale bars: $\boldsymbol{A}, \boldsymbol{C}, \boldsymbol{E}, \boldsymbol{G}, \boldsymbol{H}, 200 \mu \mathrm{m} ; \boldsymbol{B}, \boldsymbol{D}, \boldsymbol{F}, 40 \mu \mathrm{m}$.

tion (Fig. 1A,B), an Hcrt1-specific antibody (Fig. 1E,F), and transgenic fish in which EGFP expression is regulated by the hort promoter (Fig. $1 F$ ), we confirmed that hort is expressed in 7-10 neurons in the posterior hypothalamus on the fifth day of development (Faraco et al., 2006).

Mammalian Hcrt neurons project to widespread regions of the brain, including aminergic and cholinergic cells that promote arousal (Peyron et al., 1998; Chemelli et al., 1999; Date et al., 1999; Hagan et al., 1999; Horvath et al., 1999; Nambu et al., 1999; Nakamura et al., 2000). Using our hcrt-EGFP transgenic line, we observed that, by the fifth day of development, the axons of Hcrt neurons project to the four to five noradrenergic neurons of the locus ceruleus (Fig. 1G,H). We also observed extensive colocalization of Hcrt neuronal processes in the diencephalon with those of tyrosine hydroxylase-expressing dopaminergic neurons (supplemental Fig. 2, available at www.jneurosci.org as supplemental material). Double-fluorescent in situ hybridization revealed that the hort receptor is expressed in all of the diencephalic dopaminergic neurons (Fig. $1 \mathrm{~J}, K$ ) and the noradrenergic neurons of the locus ceruleus (Fig. $1 L, M$ ), suggesting that Hcrt may directly modulate the activity of these neurons. Thus, the projection pattern of Hcrt neurons during early zebrafish larval development bears striking similarities to those in adult zebrafish (Kaslin et al., 2004) and mammals (Peyron et al., 1998; Chemelli et al., 1999; Date et al., 1999; Hagan et al., 1999; Horvath et al., 1999; Nambu et al., 1999; Nakamura et al., 2000). However, unlike mammals 

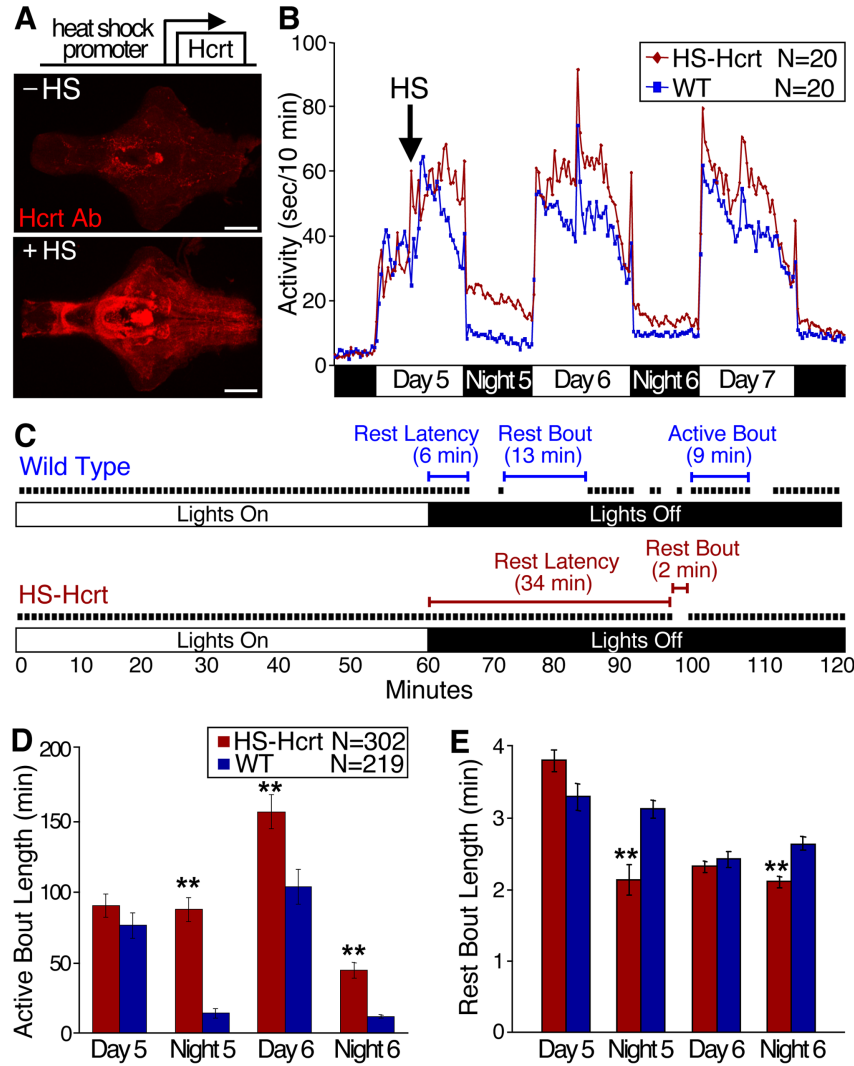

$\mathbf{F}$
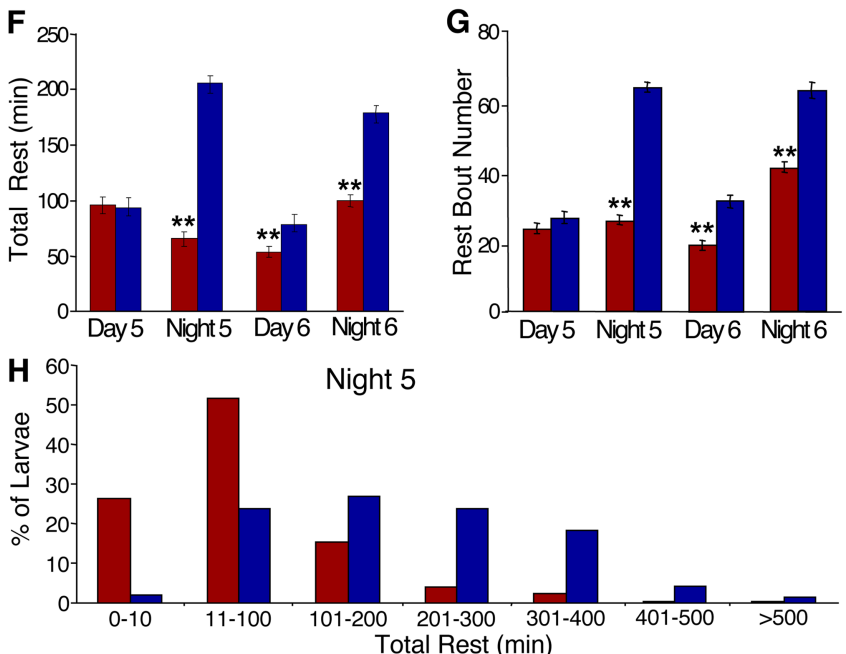

Night 5

I
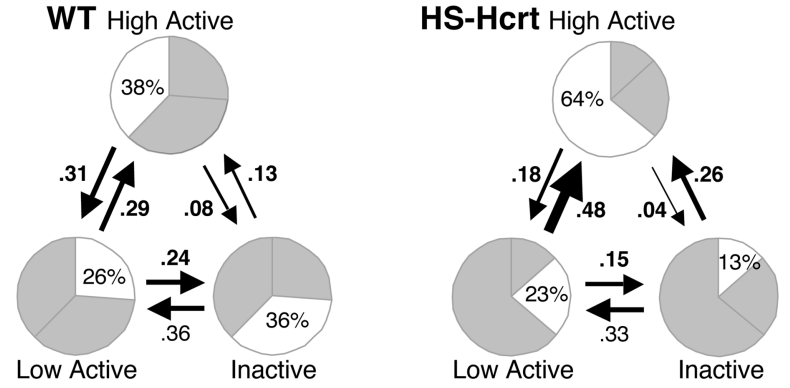

Figure 3. Hcrt overexpression consolidates active states and reduces rest. $A$, Ventral views of $7 \mathrm{~d}$ postfertilization brains labeled with an Hcrt1-specific antibody from HS-Hcrt transgenic larva that either were not (top) or were (bottom) heat shocked $48 \mathrm{~h}$ earlier. The non-heatshocked brain shows endogenous Hcrt protein, whereas the heat-shocked brain shows high Hcrt levels throughout much of the brain. Scale bars, $100 \mu \mathrm{m} . \boldsymbol{B}$, Hcrt overexpression increases locomotor activity. Each data point represents the average seconds of locomotor activity every $10 \mathrm{~min}$ for 20 larvae of each genotype. Behavioral recording was initiated on day 4 of develop- and adult zebrafish, we did not observe dense Hcrt projections to the raphe serotonergic or tuberomammillary histaminergic neurons on the fifth day of development (data not shown). Thus, at a time in development when Hcrt can modulate locomotor activity (see below), Hcrt neurons do not directly project to serotonergic or histaminergic neurons.

A recent report used an hcrt-EGFP transgene to label Hcrt neurons (Faraco et al., 2006). Using a similar reagent, we extended these studies by performing time-lapse imaging of individual Hcrt neurons and made two novel observations. First, we found that all Hcrt neurons extend their axons toward the spinal cord at similar rates but terminate at different locations (Figs. $1 \mathrm{I}$, 2) (supplemental Figs. 3-6, available at www.jneurosci.org as supplemental material) (data not shown). This contrasts with mammals, in which only a subset of Hcrt neurons project axons down the spinal cord (van den Pol, 1999), and indicates that the small number of zebrafish Hcrt neurons efficiently innervate the trunk. Second, we observed the development of extensive dendritic and axonal arbors as early as $30 \mathrm{~h}$ postfertilization (hpf) (Fig. 2A,B) (supplemental Fig. $3 A, B$, available at www.jneurosci. org as supplemental material), many of which undergo dynamic growth (Fig. 2D,F) (supplemental Figs. 5, 6, available at www. jneurosci.org as supplemental material) and retraction (supplemental Fig. 6, available at www.jneurosci.org as supplemental material) over the first 2 weeks of development. Together, these results reveal that, not only in adult mammals and adult zebrafish but also in zebrafish larvae, Hcrt is expressed in neurons in the posterior hypothalamus that project to aminergic neurons that express the Hcrt receptor. In contrast to mammals, however, zebrafish larvae have $>100$-fold fewer Hcrt neurons (de Lecea et al., 1998; Lin et al., 1999; Peyron et al., 2000), whose growth can be monitored during development. These results establish the zebrafish as a simple yet powerful system to study the development and circuitry of Hcrt neurons.

Hcrt overexpression promotes locomotor activity

The effect of ectopic Hcrt has been investigated in a variety of animals by injecting Hcrt peptide into the brain (Sakurai et al.,

ment. HS-Hcrt and WT larvae were heat shocked for $1 \mathrm{~h}$ on day 5 (arrow). HS-Hcrt and WT larvae had similar activity levels before heat shock. Hcrt-overexpressing larvae became significantly more active than WT larvae a few hours after heat shock and remained more active for over $48 \mathrm{~h}$. Note that larvae of both genotypes became very active for several minutes after lights out. The spike in activity during the afternoon on days 6 and 7 resulted from the addition of water to offset evaporation. C, Activity plots of representative WT and Hcrt-overexpressing larvae during $1 \mathrm{~h}$ preceding and after lights out. Black squares represent 1 min periods during which any locomotor activity is recorded and are referred to as active bouts. Rest latency refers to the time between lights out and the first $1 \mathrm{~min}$ period with no activity. Rest bout refers to a period of at least 1 min with no activity. $\mathbf{D}-\boldsymbol{H}$, Combined results from 10 independent experiments are shown. D-G, Each bar represents the mean \pm SEM of 302 HS-Hcrt or 219 WT larvae. Hcrt overexpression increases active bout length $(\boldsymbol{D})$, decreases rest bout length at night $(\boldsymbol{E})$, decreases total time at rest $(\boldsymbol{F})$, and decreases the number of rest bouts $(\boldsymbol{G})\left({ }^{* *} p<0.01\right.$ by two-tailed Student's $t$ test). $\boldsymbol{H}$, Hcrt overexpression reduces rest in the entire larval population. The graph represents the distribution of total rest times for HS-Hcrt and WT larvae during the night after heat shock. $I$, Pie charts represent the percentage of time spent in each state, and arrows represent the frequencies of transitions between states during the night after the heat shock. HS-Hcrt larvae in the inactive and low-active states are more likely to transition to the high-active state than WT larvae, as represented by thicker arrows. Frequency values in bold are significantly different between HS-Hcrt and WT larvae ( $p<0.05$ by two-tailed Student's $t$ test). For example, HS-Hcrt larvae spend $64 \%$ of their time in the high-active state compared with $38 \%$ for WT, and the probability that WT larvae will transition from the inactive to the high-active state is only 13 versus $26 \%$ for HS-Hcrt larvae. State transition frequencies do not add up to 1 because larvae often remain in the same state for $>1 \mathrm{~min}$. 
1998; Hagan et al., 1999; Ida et al., 1999; Yamanaka et al., 1999; Bourgin et al., 2000; John et al., 2000; Nakamura et al., 2000; Piper et al., 2000; Huang et al., 2001; Jones et al., 2001; Espana et al., 2002; Yamanaka et al., 2002; Fujiki et al., 2003; Mieda et al., 2004; Nakamachi et al., 2006). Because this technique is invasive, labor intensive, and only produces transient effects, we generated a genetic model of Hcrt overexpression that is non-invasive, easy to induce, highly reproducible, and long lasting using a heat-shock promoter to drive hort expression (HS-Hcrt) (Fig. 3A). After heat shock, these larvae express hort mRNA in all cells (supplemental Fig. $7 B, F$, available at www.jneurosci.org as supplemental material). Interestingly, overexpressed Hcrt1 peptide is only found in a subset of neurons in the CNS (Fig. 3A) (supplemental Fig. $7 D, H$, available at www.jneurosci.org as supplemental material), likely attributable to the restricted expression of a protease that cleaves the Hcrt propeptide. Mature Hcrtl peptide levels begin to increase $3 \mathrm{~h}$ after heat shock (supplemental Fig. 7, available at www.jneurosci.org as supple-

mental material) and return to normal 3-4 d later (data not shown).

To determine whether Hcrt regulates sleep/wake states in zebrafish, we characterized these behaviors in WT and HS-Hcrt larvae. The existence of sleep-like states has been established in organisms ranging from flies and zebrafish to mice and humans (Campbell and Tobler, 1984; Hendricks et al., 2000a,b; Shaw et al., 2000; Zhdanova et al., 2001; Hobson, 2005; Pack et al., 2006). Sleep studies in mammals typically use electroencephalogram recordings to define sleep and wake states based on patterns of brain activity. This technique provides precise information regarding sleep/wake states but is labor intensive and thus not ideal for high-throughput experiments (Pack et al., 2006). As an alternative means of monitoring sleep/wake states, behavioral studies have shown that sleep-like states can be identified as periods of inactivity associated with increased arousal thresholds (Campbell and Tobler, 1984; Hendricks et al., 2000a; Shaw et al., 2000; Greenspan et al., 2001; Shaw and Franken, 2003; Huber et al., 2004). Studies in Drosophila assay locomotor activity by recording interruption of an infrared beam by a moving fly, and arousal levels are measured using locomotor responses to a variety of mechanical, auditory, and thermal stimuli (Hendricks et al., 2000b; Shaw et al., 2000; Huber et al., 2004; Cirelli et al., 2005). Similarly, a study monitoring the locomotor activity of 7- to 14d-old zebrafish larvae demonstrated sleep/wake states and increased arousal thresholds in response to a mechanical stimulus at night (Zhdanova et al., 2001). To determine the earliest point in zebrafish development in which a sleep-like state could be studied, we developed an automated video-tracking system to monitor the locomotor activity of large numbers of larvae in a high-throughput manner (Fig. 4). Individual larvae were placed in each of 80 wells of a 96-well plate on the fourth day of development, and the locomotor activity of each larva was monitored for several days using an infrared camera. We defined an active bout as a period of at least 1 min with any detectable activity (Fig. $3 C$ ). A rest bout was defined as a $1 \mathrm{~min}$ period with zero activity, because 1 min of inactivity is associated with significant changes in arousal threshold, as is observed in sleep (see below). We observed that WT larvae exhibit robust locomotor activity beginning on the fifth day of development and are much more active during the day than at night (Fig. 5A,B) (Hurd and Cahill, 2002). Hcrt overexpression significantly increases locomotor activity (Fig. $3 B$ ) and the length of active bouts (Fig. 3C,D) during both the day and night (for movies, see http://www.mcb.harvard.edu/ schier). For example, the average active bout length during the night after heat shock is $87 \mathrm{~min}$ in Hcrt-overexpressing larvae and $14 \mathrm{~min}$ in WT. These results suggest that Hcrt overexpression stimulates locomotor activity and consolidates active states. Hcrt-overexpressing larvae also spend less time in the resting state (Fig. $3 F, H$ ) and have significantly fewer (Fig. $3 C, G$ ) and shorter (Fig. 3C,E) rest bouts. These effects are particularly prominent at night. For example, on the night after heat shock, Hcrtoverexpressing larvae have an average of 26 rest bouts compared with 64 for WT, and Hcrt-overexpressing larvae have a median sleep latency of 77 min compared with 13 min for WT. Thus, Hcrt-overexpressing larvae are severely impaired in their ability to both initiate and maintain the resting state at night, displaying the hallmark symptoms of insomnia (American Academy of Sleep Medicine, 2001; Mahowald and Schenck, 2005).

\section{Hcrt overexpression decreases arousal threshold}

We next developed and applied an assay to test whether Hcrt modulates arousal thresholds, a key criterion for sleep/wake regulators. We found that most larvae become active for several minutes after exposure to sudden darkness, perhaps in response to a perceived threat such as the shadow of a predator (Fig. $5 C, D$ ) (for movie, see http://www.mcb.harvard.edu/schier). Almost all larvae become active within $15 \mathrm{~s}$ of dark onset if they display any activity during the previous minute (Fig. $6 \mathrm{~A}$ ). In contrast, $1 \mathrm{~min}$ or more of rest immediately before dark onset reduces the number of responding WT larvae (Fig. 6A) and increases the average response latency (Fig. $6 B$ ). These results indicate that rest before 

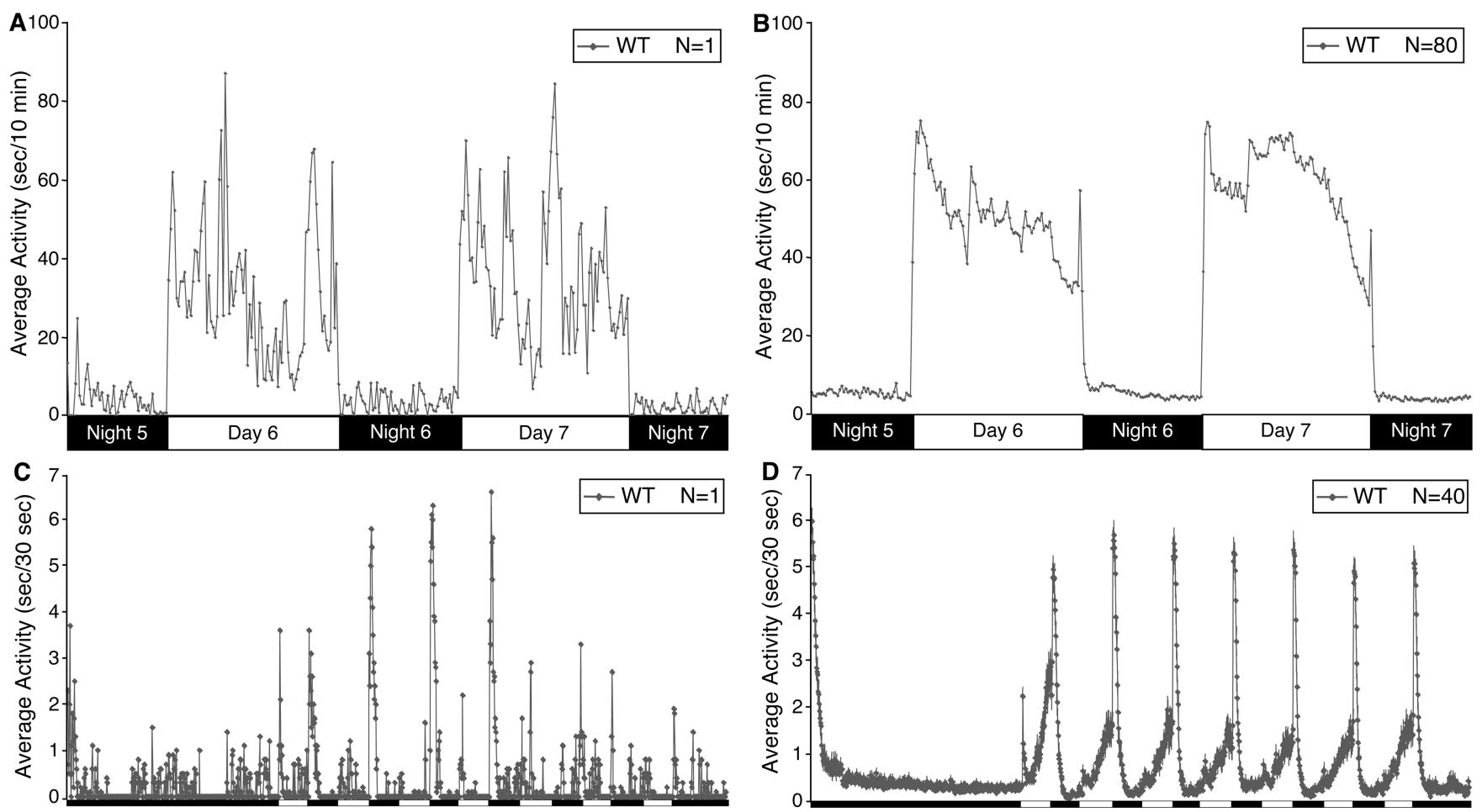

Figure 5. Characterization of wild-type larval zebrafish sleep/wake locomotor behavior. $\boldsymbol{A}, \boldsymbol{B}$, Each data point represents the seconds of locomotor activity every $10 \mathrm{~min}$ for a single larva ( $\boldsymbol{A}$ ) or averaged for 80 larvae (B). As shown in previous studies (Hurd and Cahill, 2002; Kaneko and Cahill, 2005), we found that zebrafish larvae exhibit high locomotor activity levels during the day and low levels at night beginning on the fifth day of development. Larvae move in short bursts of activity followed by pauses, such that the total amount of time a single larva moves each minute is typically 4-10 s during the day and $0-1 \mathrm{~s}$ at night. $\boldsymbol{C}, \boldsymbol{D}$, Pulses of sudden darkness provide a non-invasive assay of arousal levels. Each data point represents the seconds of locomotor activity every $30 \mathrm{~s}$ for a single larva $(\boldsymbol{C})$ or averaged for 40 larvae (D). Larvae were exposed to alternating 30 min periods of light and darkness during the night. Individual larvae respond to most dark stimuli (C). No attenuation in the response was observed after multiple light/dark stimuli.

dark onset increases arousal thresholds in WT larvae. Responses after 2 or more minutes of rest are not significantly different from those after 1 min of rest (Fig. $6 A, B$ ), indicating that as little as 1 min of rest can be considered a sleep-like state. Strikingly, Hcrtoverexpressing larvae have lower arousal thresholds than WT larvae. A larger proportion of Hcrt-overexpressing larvae respond to darkness after rest (Fig. 6A), and response latency is shorter for Hcrt-overexpressing larvae compared with WT (Fig. $6 B)$. Thus, Hcrt-overexpressing larvae have reduced arousal thresholds and, similar to humans with chronic insomnia, are hypersensitive to arousing stimuli (Bonnet and Arand, 2000; American Academy of Sleep Medicine, 2001; Nofzinger et al., 2004; Mahowald and Schenck, 2005).

\section{Hcrt overexpression affects transitions between active and inactive states}

As an alternative means of assaying arousal levels in Hcrtoverexpressing larvae, we investigated the nature of transitions between active and resting states. We subdivided the active state into a high-active state (active for $>1 \mathrm{~s}$ per minute) and a lowactive state (active for $<1 \mathrm{~s}$ per minute) and determined the frequency at which a larva switches among all states. For example, when WT larvae are in the inactive state at night, they transition into the low-active state with a frequency of $36 \%$ and into the high-active state with a frequency of $13 \%$ (Fig. 3I). Thus, when WT larvae transition from resting to waking, they are more likely to first enter a low-active state before becoming more highly active. Hcrt-overexpressing larvae at rest have similar transition rates into the low-active state (frequency of 33\% for HS-Hcrt vs $36 \%$ for WT) but are twice as likely as WT to become highly active directly from rest (frequency of $26 \%$ for HS-Hcrt vs $13 \%$ for WT) (Fig. 3I). Furthermore, Hcrt-overexpressing larvae spend almost twice as much time in the high-active state and a third as much time in the inactive state as WT. Thus, Hcrt overexpression destabilizes the inactive and low-active states in favor of the highactive state. These results are consistent with our finding that Hcrt-overexpressing larvae are hyperaroused (Fig. 6).

\section{Interactions between hcrt and the circadian system}

Hcrt-overexpressing larvae are less active at night than during the day, revealing that Hcrt signaling modulates but does not extinguish circadian regulation of locomotor activity (Fig. 3B). Conversely, we asked whether normal circadian oscillations are required for Hcrt to increase locomotor activity. Such experiments have not been performed in other systems because inducible, long-term Hcrt expression systems have not been established. WT larvae raised in either constant dark (DD) or constant light (LL) conditions exhibit little or no oscillation in their locomotor activity (supplemental Fig. 8, available at www.jneurosci.org as supplemental material) (Hurd and Cahill, 2002). Remarkably, Hcrt overexpression increases locomotor activity and decreases rest in larvae raised in either DD (Fig. 7) or LL (supplemental Fig. 9, available at www.jneurosci.org as supplemental material). This effect is particularly dramatic in DD conditions, in which WT larvae exhibit very low activity levels. For example, in Hcrtoverexpressing larvae, the average active bout length increases 23 -fold and the number of sleep bouts decreases sevenfold compared with WT from 12-24 h after heat shock. Furthermore, the effects of Hcrt overexpression are much greater in DD or LL than in larvae maintained in $14 / 10 \mathrm{~h} \mathrm{LD}$ conditions. For example, 


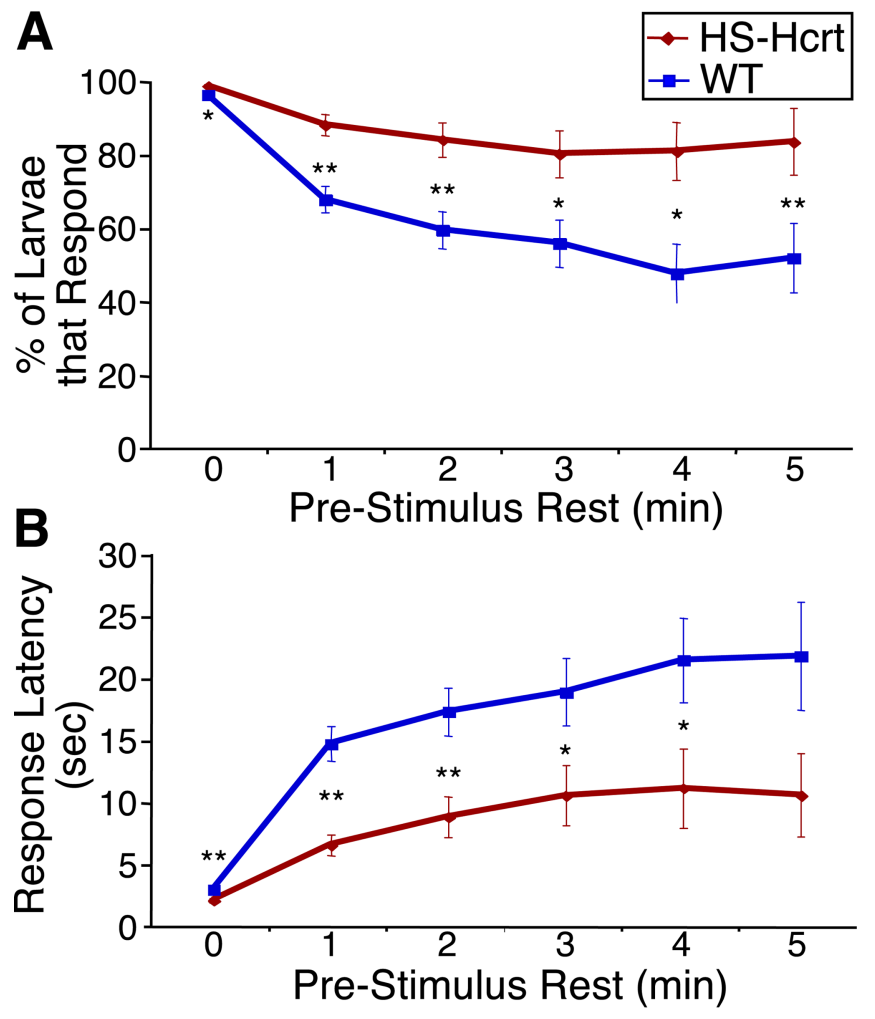

Figure 6. Hcrt overexpression decreases arousal threshold. A, Hcrt overexpression increases the response rate to sudden darkness. Each data point represents the percentage of larvae that become active within $15 \mathrm{~s}$ of sudden darkness, after continuous rest for at least the indicated periods of time. Nearly $100 \%$ of larvae of both genotypes respond to a dark stimulus if they were active during the previous minute. One minute of prestimulus rest reduces the response rate by $30 \%$ for WT larvae but only by $10 \%$ for Hcrt-overexpressing larvae. For each time point analyzed, significantly more Hcrt-overexpressing larvae respond than WT larvae $\left({ }^{*} p<0.05\right.$; ${ }^{* *} p<0.01$ by $\chi^{2}$ test). $\boldsymbol{B}$, Hcrt overexpression reduces the response latency to sudden darkness. Each data point represents the average elapsed time between initiation of the dark stimulus and the onset of locomotor activity, after continuous rest for at least the indicated periods of time. Hcrt-overexpressing larvae respond significantly faster than WT larvae $\left({ }^{*} p<0.05\right.$; ${ }^{* *} p<0.01$ by two-tailed Student's $t$ test). One minute of prestimulus rest increases the response latency by fivefold for WT larvae but only by threefold for Hcrt-overexpressing larvae. Even after at least 5 min of continuous rest, the response latency of WT larvae is twice that of Hcrt-overexpressing larvae. For both genotypes in $\boldsymbol{A}$ and $\boldsymbol{B}$, responses after 1 or more minutes of prestimulus rest are all significantly different from those after 0 min of rest $(p<0.001)$. Responses after 2 or more minutes of prestimulus rest are not significantly different from those after $1 \mathrm{~min}$ of rest $(p>0.05)$. A total of $780 \mathrm{HS}$-Hort and 800 WT responses from three experiments were analyzed.

during the night after heat shock, the average active bout length of Hcrt-overexpressing larvae is $>2.5$-fold longer in DD or LL than in LD (compare Figs. 3D, 7B) (supplemental Fig. 9B, available at www.jneurosci.org as supplemental material), and Hcrtoverexpressing larvae in DD or LL spend less than half as much time at rest as larvae in LD (compare Figs. 3F, 7D) (supplemental Fig. $9 D$, available at www.jneurosci.org as supplemental material).

Dramatic differences in state transitions were also observed under constant lighting conditions. For example, in DD conditions, Hcrt-overexpressing larvae are far more likely than WT to transition from the inactive to the high-active state (frequency of $53 \%$ for HS-Hcrt vs $15 \%$ for WT) (Fig. 7G). HS-Hcrt larvae are also far more likely than WT larvae to transition from the lowactive to the high-active state (frequency of $71 \%$ for HS-Hcrt vs $28 \%$ for WT) and far less likely to transition into the inactive state from either active state (HS-Hcrt low-active to inactive fre- quency, 8 vs $21 \%$ for WT; HS-Hcrt high-active to inactive frequency, 2 vs $10 \%$ for WT) (Fig. $7 G$ ). The effect of overexpressed Hcrt in DD or LL is also greater than in LD. For example, Hcrtoverexpressing larvae spend $64 \%$ of the time in the high-active state in LD (Fig. 3I) but 86 or $90 \%$ of the time in DD or LL conditions, respectively (Fig. 7G) (supplemental Fig. 9G, available at www.jneurosci.org as supplemental material). Furthermore, Hcrt-overexpressing larvae transition directly from the inactive to the high-active state $26 \%$ of the time in LD but 53 or $46 \%$ of the time in DD or LL conditions, respectively. Because the effect of overexpressed Hcrt in DD or LL conditions is significantly greater than in $\mathrm{LD}$, we conclude that normal circadian oscillations dampen the effects of Hcrt signaling. These results also demonstrate that Hcrt can function in the absence of normal circadian oscillations in locomotor activity.

\section{Discussion}

Our results reveal that the neural circuitry and function of the Hcrt system is conserved from mammals to zebrafish. We find that 5-d-old wild-type larvae exhibit robust locomotive sleep/ wake behaviors and have higher arousal thresholds during periods of rest, indicative of a sleep-like state (Campbell and Tobler, 1984; Hendricks et al., 2000a; Shaw et al., 2000; Greenspan et al., 2001; Zhdanova et al., 2001; Shaw and Franken, 2003). Our inducible Hcrt transgenic expression system reveals that Hcrtoverexpressing larvae are hyperaroused and have dramatically reduced abilities to initiate and maintain a sleep-like state, similar to humans with insomnia (Bonnet and Arand, 2000; American Academy of Sleep Medicine, 2001; Nofzinger et al., 2004; Mahowald and Schenck, 2005). Strikingly, Hcrt can increase locomotor activity independent of normal circadian oscillations in locomotor activity, and these oscillations dampen the effects of Hcrt overexpression. Because our experiments were performed on larvae, the results are not confounded by previous experience, feeding, thermoregulation, social interactions, or other complex homeostatic processes or behaviors in which Hcrt has been implicated in mammals (Sakurai et al., 1998; Szekely et al., 2002; Yamanaka et al., 2003; Harris et al., 2005; Borgland et al., 2006; D'Anna and Gammie, 2006). Our experiments therefore clarify the primary function of Hcrt and suggest that the most basal and ancestral role of Hcrt signaling is the promotion of wakefulness. Our experiments also establish zebrafish as a system to study the genetics and neural circuitry of sleep.

Our results indicate that the Hcrt neural circuit in zebrafish larvae has strong similarity to its counterparts in adult zebrafish and mammals. Hcrt is exclusively expressed in the zebrafish posterior hypothalamus (Fig. 1) (Kaslin et al., 2004; Faraco et al., 2006) as in mammals (de Lecea et al., 1998; Sakurai et al., 1998), but zebrafish have $>100$-fold fewer Hcrt neurons (de Lecea et al., 1998; Sakurai et al., 1998; Lin et al., 1999; Peyron et al., 2000). Although this highly specific expression is regulated at the transcriptional level, our misexpression studies suggest that posttranscriptional mechanisms can also limit production of mature Hcrt peptide (supplemental Fig. 7, available at www.jneurosci.org as supplemental material). Larval zebrafish Hcrt neurons project to diencephalic dopaminergic neurons and the noradrenergic neurons of the locus ceruleus, as they do in mammals (Peyron et al., 1998; Chemelli et al., 1999; Date et al., 1999; Hagan et al., 1999; Horvath et al., 1999; Nambu et al., 1999; Nakamura et al., 2000) and adult zebrafish (Kaslin et al., 2004). These neurons express the single zebrafish Hcrt receptor ortholog, indicating that they are likely directly activated by Hcrt. In contrast to mammals (Peyron et al., 1998; Date et al., 1999; Nambu et al., 1999) and 

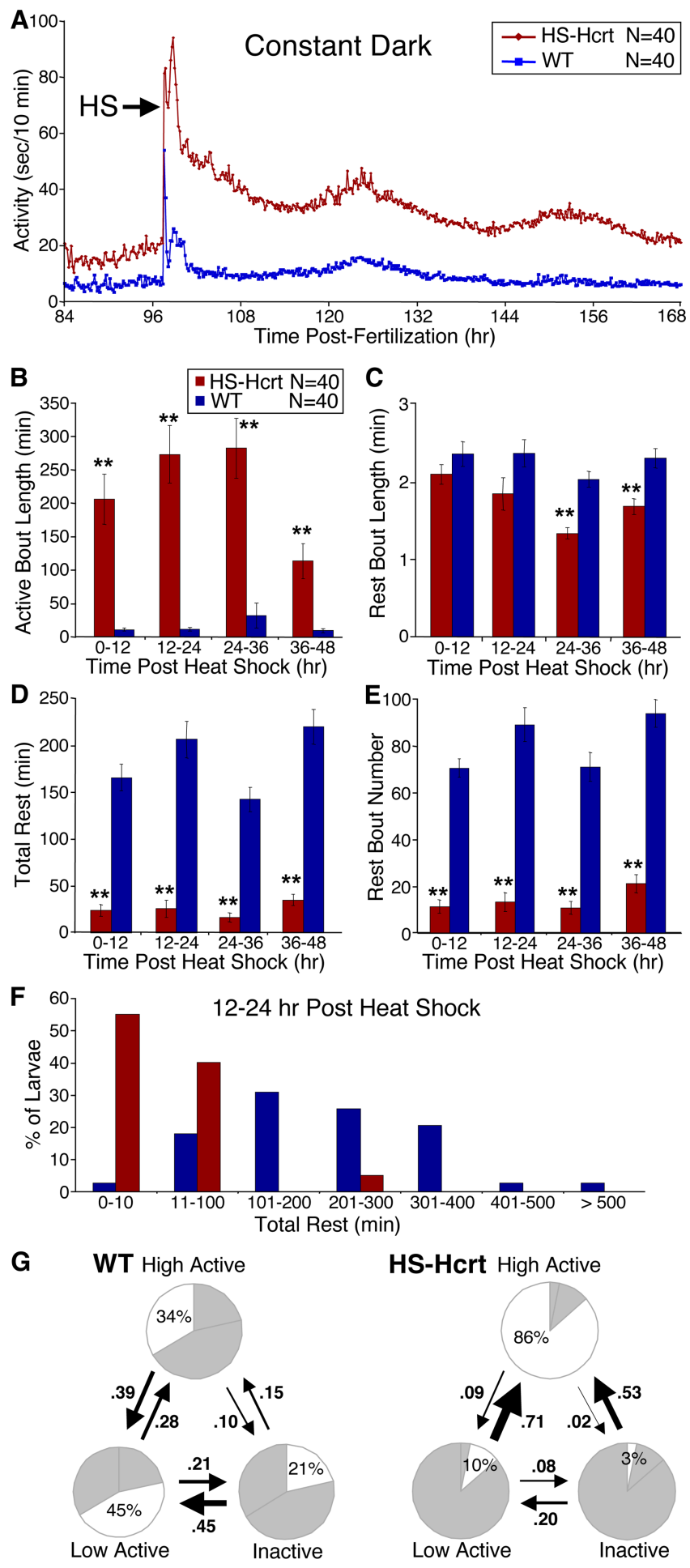

Figure 7. Hcrt overexpression dramatically consolidates active states and reduces rest in constant dark conditions. $\boldsymbol{A}$, Hcrt overexpression dramatically increases locomotor activity in DD conditions. Each data point represents the average seconds of locomotor activity every $10 \mathrm{~min}$ for 40 larvae of each genotype. Embryos were exposed to light for 2-3 $\mathrm{h}$ after fertilization but were then raised in the dark. Behavioral recording was initiated on day 4 of development, and larvae were heat shocked for $1 \mathrm{~h}$ on day 5 (arrow). Larvae exhibit activity levels in DD similar to those observed during the dark phase of a 14/10 h light/dark cycle. Hcrt-overexpressing larvae are slightly more active than WT larvae before heat shock, presumably attributable to leaky expression driven by the heat-shock promoter, but become significantly more active after heat shock. The slight oscillation in locomotor activity after heat shock likely results from the exposure to low levels of red light immediately before and after heat shock, to handling of the 96-well plate as it is transferred to the $37^{\circ} \mathrm{C}$ water bath, or to the temperature stimulus of the heat shock itself. $\boldsymbol{B}-\boldsymbol{E}$, Each bar represents the mean \pm SEM of 40 larvae. Hcrt overexpression adult zebrafish (Kaslin et al., 2004), we do not observe Hcrt projections to the raphe serotonergic or tuberomammillary histaminergic neurons on the fifth day of development. Thus, at a time in development when Hcrt can regulate locomotor activity, direct modulation of serotonergic and histaminergic neurons may not be necessary to mediate Hcrt function and may therefore reveal the basic neural circuitry required for Hcrt function. Moreover, zebrafish brains lack a cortex, indicating that their relatively basal brain structures are sufficient to mediate Hcrt function. The accessibility of zebrafish for in vivo imaging (Higashijima et al., 2003; Gahtan and Baier, 2004) and the small number of Hcrt neurons should make zebrafish a powerful system to study the development and function of Hcrt neural circuits.

To generate a non-invasive, inducible, and robust model of Hcrt overexpression, we created transgenic zebrafish that express Hcrt under the control of a heat-shock promoter. Most previous Hcrt overexpression studies required the invasive and labor-intensive injection of Hcrt peptide into the brain, which increased wakefulness and inhibited rest for only a few hours, and thus required that behavior be assayed immediately after handling the animal (Sakurai et al., 1998; Hagan et al., 1999; Ida et al., 1999; Bourgin et al., 2000; John et al., 2000; Nakamura et al., 2000; Piper et al., 2000; Huang et al., 2001; Jones et al., 2001; Espana et al., 2002; Yamanaka et al., 2002; Fujiki et al., 2003; Nakamachi et al., 2006). One study used transgenic mice that constitutively overexpressed Hcrt in the brain to rescue Hcrt deficiency, but the effects of Hcrt-overexpression on wild-type behavior were not described (Mieda et al., 2004). In contrast to these studies, our transgenic fish express high levels of Hcrt for at least $3 \mathrm{~d}$, allowing us to assay behavior long after the heat shock. We find that Hcrt overexpression promotes and consolidates active states, decreases the frequency and length of rest bouts, increases sleep latency after lights out, and decreases arousal threshold. Hcrt-overexpressing larvae also spend more time in highly active states compared with wild-type and are more likely to transition from states of no or low activity into a high-activity state. Our findings indicate that long-term overexpression of Hcrt increases wakefulness and arousal, whereas long-term absence of Hcrt in mice and humans reduces wakefulness and arousal. However, both loss- and gain-of-Hcrt function result in altered sleep/ wake states and abnormal transitions between activity states (Chemelli et al., 1999; Hara et al., 2001; Willie et al., 2003; Mochizuki et al., 2004). Thus, Hcrt levels must be tightly regulated to allow optimal control of sleep/wake states, providing a potential challenge to the development of therapeutics that target the Hcrt system.

We found that Hcrt-overexpressing larvae are hyperaroused and have impaired abilities to initiate and maintain rest at night, thus displaying similar behavioral characteristics as humans with insomnia (American Academy of Sleep Medicine, 2001). Although there is no direct evidence implicating Hcrt in insomnia, it has been proposed that chronic insomnia is a general disorder

\section{$\leftarrow$}

increases active bout length $(\boldsymbol{B})$, decreases rest bout length $(\boldsymbol{C})$, decreases total time at rest $(\boldsymbol{D})$, and decreases the number of rest bouts $(\boldsymbol{E})$ in DD conditions $\left({ }^{* *} p<0.01\right.$ by two-tailed Student's $t$ test). $\boldsymbol{F}$, Hcrt overexpression decreases rest in the entire larval population in DD conditions. The graph represents the distribution of total rest times for HS-Hcrt and WT larvae 12-24 h after heat shock. G, Pie charts represent the percentage of time spent in each state, and arrows represent the frequencies of transitions between states during the $12 \mathrm{~h}$ after the heat shock. HS-Hcrt larvae in the inactive and low-active states are more likely to transition to the highactive state than WT larvae, as represented by thicker arrows. All frequency values are significantly different between HS-Hcrt and WT larvae ( $p<0.05$ by two-tailed Student's $t$ test). 
of hyperarousal that may involve dysfunction of the Hcrt system (Horvath and Gao, 2005; Saper et al., 2005). In fact, Hcrt neurons are regulated by minimal inhibitory input, making them susceptible to abnormal excitation (Horvath and Gao, 2005). Although one study found normal Hcrt levels in human subjects with insomnia (Mignot et al., 2002), only 12 subjects were studied. Furthermore, this study would not detect other Hcrt-dependent effects, such as hyperactivity of Hcrt-expressing neurons or activation of Hcrt signaling downstream of the Hcrt ligand. Although models with reduced sleep have been generated via brain lesions in mammals (Lu et al., 2000) or through genetic loss-offunction in Drosophila (Cirelli et al., 2005), our novel gain-offunction model is uniquely suited for the large-scale testing of environmental signals and drugs that suppress insomnia in vertebrates. Such models are urgently needed, because insomnia accounts for $\sim 50 \%$ of sleep-related complaints (Colten and $\mathrm{Al}$ tevog, 2006).

Our experiments reveal novel interactions between Hcrt signaling and the circadian system that were not identified previously because a long-term Hcrt overexpression system was not available. First, Hcrt-overexpressing larvae are less active at night than during the day. This indicates that Hcrt-overexpression modulates but does not abolish the effects of the circadian system on locomotor activity. Second, Hcrt overexpression more dramatically increases locomotor activity under constant lighting conditions, in which larvae exhibit little or no oscillation in locomotor activity. Previous studies showed that the mammalian suprachiasmatic nucleus ( $\mathrm{SCN}$ ), which acts as the master pacemaker for circadian rhythms in vertebrates, indirectly projects to Hcrt neurons (Abrahamson et al., 2001; Aston-Jones et al., 2001; Chou et al., 2003; Deurveilher and Semba, 2005; Yoshida et al., 2006) and that Hcrt levels fluctuate with a circadian rhythm that is abolished after SCN ablation (Deboer et al., 2004; Zhang et al., 2004). These findings suggest that the circadian system regulates Hcrt levels, perhaps by regulating the activity of Hcrt neurons. However, it has also been shown that Hcrt signaling is not necessary for the normal circadian amplitude and timing of sleep/wake rhythms (Mochizuki et al., 2004), indicating that the circadian system can function independently of Hcrt signaling. Interestingly, SCN neurons indirectly project to and regulate the activity of locus ceruleus neurons (Aston-Jones et al., 2001), suggesting that both the circadian and Hcrt systems likely regulate sleep/ wake states, at least in part, by modulating the activity of locus ceruleus neurons. Together, the mammalian loss-of-function and our gain-of-function studies suggest that the Hcrt and circadian systems can function independently of each other but also appear to cross regulate. Additional study is required to clearly determine whether the circadian and Hcrt systems use separate or common mechanisms to regulate sleep/wake states.

More generally, our study establishes zebrafish as a model system for the genetic analysis of sleep. Zebrafish will complement mammals and Drosophila because it combines the experimental amenability of Drosophila (Driever et al., 1996; Granato et al., 1996; Hendricks et al., 2000a; Greenspan et al., 2001; Orger et al., 2004; Gross et al., 2005; Zon and Peterson, 2005) with neural substrates similar to mammals (Reichert et al., 1996; Mueller and Wullimann, 2005). Our high-throughput, quantitative system to assay locomotor activity and arousal in zebrafish allows us to simultaneously analyze hundreds of larvae. A similar technology has provided the basis for large-scale genetic screens in Drosophila (Cirelli et al., 2005). Our system should therefore allow highthroughput zebrafish screens for novel genes and drugs that regulate sleep.

\section{References}

Abrahamson EE, Leak RK, Moore RY (2001) The suprachiasmatic nucleus projects to posterior hypothalamic arousal systems. NeuroReport 12:435-440.

American Academy of Sleep Medicine (2001) ICSD_International classification of sleep disorders, revised: diagnostic and coding manual. Chicago: American Academy of Sleep Medicine.

Aston-Jones G, Chen S, Zhu Y, Oshinsky ML (2001) A neural circuit for circadian regulation of arousal. Nat Neurosci 4:732-738.

Bonnet MH, Arand DL (2000) Activity, arousal, and the MSLT in patients with insomnia. Sleep 23:205-212.

Borgland SL, Taha SA, Sarti F, Fields HL, Bonci A (2006) Orexin A in the VTA is critical for the induction of synaptic plasticity and behavioral sensitization to cocaine. Neuron 49:589-601.

Bourgin P, Huitron-Resendiz S, Spier AD, Fabre V, Morte B, Criado JR, Sutcliffe JG, Henriksen SJ, de Lecea L (2000) Hypocretin-1 modulates rapid eye movement sleep through activation of locus ceruleus neurons. J Neurosci 20:7760-7765.

Campbell SS, Tobler I (1984) Animal sleep: a review of sleep duration across phylogeny. Neurosci Biobehav Rev 8:269-300.

Chemelli RM, Willie JT, Sinton CM, Elmquist JK, Scammell T, Lee C, Richardson JA, Williams SC, Xiong Y, Kisanuki Y, Fitch TE, Nakazato M, Hammer RE, Saper CB, Yanagisawa M (1999) Narcolepsy in orexin knockout mice: molecular genetics of sleep regulation. Cell 98:437-451.

Chou TC, Scammell TE, Gooley JJ, Gaus SE, Saper CB, Lu J (2003) Critical role of dorsomedial hypothalamic nucleus in a wide range of behavioral circadian rhythms. J Neurosci 23:10691-10702.

Cirelli C, Bushey D, Hill S, Huber R, Kreber R, Ganetzky B, Tononi G (2005) Reduced sleep in Drosophila Shaker mutants. Nature 434:1087-1092.

Colten HR, Altevog BM (2006) Sleep disorders and sleep deprivation: an unmet public health problem. Washington, DC: National Academy of Sciences.

D’Anna KL, Gammie SC (2006) Hypocretin-1 dose-dependently modulates maternal behaviour in mice. J Neuroendocrinol 18:553-566.

Date Y, Ueta Y, Yamashita H, Yamaguchi H, Matsukura S, Kangawa K, Sakurai T, Yanagisawa M, Nakazato M (1999) Orexins, orexigenic hypothalamic peptides, interact with autonomic, neuroendocrine and neuroregulatory systems. Proc Natl Acad Sci USA 96:748-753.

Deboer T, Overeem S, Visser NA, Duindam H, Frolich M, Lammers GJ, Meijer JH (2004) Convergence of circadian and sleep regulatory mechanisms on hypocretin-1. Neuroscience 129:727-732.

de Lecea L, Kilduff TS, Peyron C, Gao X, Foye PE, Danielson PE, Fukuhara C, Battenberg EL, Gautvik VT, Bartlett II FS, Frankel WN, van den Pol AN, Bloom FE, Gautvik KM, Sutcliffe JG (1998) The hypocretins: hypothalamus-specific peptides with neuroexcitatory activity. Proc Natl Acad Sci USA 95:322-327.

Deurveilher S, Semba K (2005) Indirect projections from the suprachiasmatic nucleus to major arousal-promoting cell groups in rat: implications for the circadian control of behavioural state. Neuroscience 130:165-183.

Driever W, Solnica-Krezel L, Schier AF, Neuhauss SC, Malicki J, Stemple DL, Stainier DY, Zwartkruis F, Abdelilah S, Rangini Z, Belak J, Boggs C (1996) A genetic screen for mutations affecting embryogenesis in zebrafish. Development 123:37-46.

Espana RA, Plahn S, Berridge CW (2002) Circadian-dependent and circadian-independent behavioral actions of hypocretin/orexin. Brain Res 943:224-236.

Faraco JH, Appelbaum L, Marin W, Gaus SE, Mourrain P, Mignot E (2006) Regulation of hypocretin (OREXIN) expression in embryonic zebrafish. J Biol Chem 281:29753-29761.

Fujiki N, Yoshida Y, Ripley B, Mignot E, Nishino S (2003) Effects of IV and ICV hypocretin-1 (orexin A) in hypocretin receptor-2 gene mutated narcoleptic dogs and IV hypocretin-1 replacement therapy in a hypocretinligand-deficient narcoleptic dog. Sleep 26:953-959.

Gahtan E, Baier H (2004) Of lasers, mutants, and see-through brains: functional neuroanatomy in zebrafish. J Neurobiol 59:147-161.

Granato M, van Eeden FJ, Schach U, Trowe T, Brand M, Furutani-Seiki M, Haffter P, Hammerschmidt M, Heisenberg CP, Jiang YJ, Kane DA, Kelsh RN, Mullins MC, Odenthal J, Nusslein-Volhard C (1996) Genes controlling and mediating locomotion behavior of the zebrafish embryo and larva. Development 123:399-413.

Greenspan RJ, Tononi G, Cirelli C, Shaw PJ (2001) Sleep and the fruit fly. Trends Neurosci 24:142-145. 
Gross JM, Perkins BD, Amsterdam A, Egana A, Darland T, Matsui JI, Sciascia S, Hopkins N, Dowling JE (2005) Identification of zebrafish insertional mutants with defects in visual system development and function. Genetics 170:245-261.

Hagan JJ, Leslie RA, Patel S, Evans ML, Wattam TA, Holmes S, Benham CD, Taylor SG, Routledge C, Hemmati P, Munton RP, Ashmeade TE, Shah AS, Hatcher JP, Hatcher PD, Jones DN, Smith MI, Piper DC, Hunter AJ, Porter RA, Upton N (1999) Orexin A activates locus coeruleus cell firing and increases arousal in the rat. Proc Natl Acad Sci USA 96:10911-10916.

Halloran MC, Sato-Maeda M, Warren JT, Su F, Lele Z, Krone PH, Kuwada JY, Shoji W (2000) Laser-induced gene expression in specific cells of transgenic zebrafish. Development 127:1953-1960.

Hara J, Beuckmann CT, Nambu T, Willie JT, Chemelli RM, Sinton CM, Sugiyama F, Yagami K, Goto K, Yanagisawa M, Sakurai T (2001) Genetic ablation of orexin neurons in mice results in narcolepsy, hypophagia, and obesity. Neuron 30:345-354.

Harris GC, Wimmer M, Aston-Jones G (2005) A role for lateral hypothalamic orexin neurons in reward seeking. Nature 437:556-559.

Hendricks JC, Sehgal A, Pack AI (2000a) The need for a simple animal model to understand sleep. Prog Neurobiol 61:339-351.

Hendricks JC, Finn SM, Panckeri KA, Chavkin J, Williams JA, Sehgal A, Pack AI (2000b) Rest in Drosophila is a sleep-like state. Neuron 25:129-138.

Higashijima S, Masino MA, Mandel G, Fetcho JR (2003) Imaging neuronal activity during zebrafish behavior with a genetically encoded calcium indicator. J Neurophysiol 90:3986-3997.

Hobson JA (2005) Sleep is of the brain, by the brain and for the brain. Nature 437:1254-1256.

Horvath TL, Gao XB (2005) Input organization and plasticity of hypocretin neurons: possible clues to obesity's association with insomnia. Cell Metab 1:279-286.

Horvath TL, Peyron C, Diano S, Ivanov A, Aston-Jones G, Kilduff TS, van Den Pol AN (1999) Hypocretin (orexin) activation and synaptic innervation of the locus coeruleus noradrenergic system. J Comp Neurol 415:145-159.

Hsiao CD, Hsieh FJ, Tsai HJ (2001) Enhanced expression and stable transmission of transgenes flanked by inverted terminal repeats from adenoassociated virus in zebrafish. Dev Dyn 220:323-336.

Huang ZL, Qu WM, Li WD, Mochizuki T, Eguchi N, Watanabe T, Urade Y, Hayaishi O (2001) Arousal effect of orexin A depends on activation of the histaminergic system. Proc Natl Acad Sci USA 98:9965-9970.

Huber R, Hill SL, Holladay C, Biesiadecki M, Tononi G, Cirelli C (2004) Sleep homeostasis in Drosophila melanogaster. Sleep 27:628-639.

Hurd MW, Cahill GM (2002) Entraining signals initiate behavioral circadian rhythmicity in larval zebrafish. J Biol Rhythms 17:307-314.

Ida T, Nakahara K, Katayama T, Murakami N, Nakazato M (1999) Effect of lateral cerebroventricular injection of the appetite-stimulating neuropeptide, orexin and neuropeptide $\mathrm{Y}$, on the various behavioral activities of rats. Brain Res 821:526-529.

John J, Wu MF, Siegel JM (2000) Systemic administration of hypocretin-1 reduces cataplexy and normalizes sleep and waking durations in narcoleptic dogs. Sleep Res Online 3:23-28.

Jones DN, Gartlon J, Parker F, Taylor SG, Routledge C, Hemmati P, Munton RP, Ashmeade TE, Hatcher JP, Johns A, Porter RA, Hagan JJ, Hunter AJ, Upton N (2001) Effects of centrally administered orexin-B and orexin-A: a role for orexin-1 receptors in orexin-B-induced hyperactivity. Psychopharmacology (Berl) 153:210-218.

Kaneko M, Cahill GM (2005) Light-dependent development of circadian gene expression in transgenic zebrafish. PLoS Biol 3:e34.

Kaslin J, Nystedt JM, Ostergard M, Peitsaro N, Panula P (2004) The orexin/ hypocretin system in zebrafish is connected to the aminergic and cholinergic systems. J Neurosci 24:2678-2689.

Lin L, Faraco J, Li R, Kadotani H, Rogers W, Lin X, Qiu X, de Jong PJ, Nishino S, Mignot E (1999) The sleep disorder canine narcolepsy is caused by a mutation in the hypocretin (orexin) receptor 2 gene. Cell 98:365-376.

Lu J, Greco MA, Shiromani P, Saper CB (2000) Effect of lesions of the ventrolateral preoptic nucleus on NREM and REM sleep. J Neurosci 20:3830-3842.

Mahowald MW, Schenck CH (2005) Insights from studying human sleep disorders. Nature 437:1279-1285.

Mieda M, Willie JT, Hara J, Sinton CM, Sakurai T, Yanagisawa M (2004)
Orexin peptides prevent cataplexy and improve wakefulness in an orexin neuron-ablated model of narcolepsy in mice. Proc Natl Acad Sci USA 101:4649-4654.

Mignot E, Lammers GJ, Ripley B, Okun M, Nevsimalova S, Overeem S, Vankova J, Black J, Harsh J, Bassetti C, Schrader H, Nishino S (2002) The role of cerebrospinal fluid hypocretin measurement in the diagnosis of narcolepsy and other hypersomnias. Arch Neurol 59:1553-1562.

Mochizuki T, Crocker A, McCormack S, Yanagisawa M, Sakurai T, Scammell TE (2004) Behavioral state instability in orexin knock-out mice. J Neurosci 24:6291-6300.

Mueller T, Wullimann MF (2005) Atlas of early zebrafish development. Oxford: Elsevier.

Nakamachi T, Matsuda K, Maruyama K, Miura T, Uchiyama M, Funahashi H, Sakurai T, Shioda S (2006) Regulation by orexin of feeding behaviour and locomotor activity in the goldfish. J Neuroendocrinol 18:290-297.

Nakamura T, Uramura K, Nambu T, Yada T, Goto K, Yanagisawa M, Sakurai $\mathrm{T}$ (2000) Orexin-induced hyperlocomotion and stereotypy are mediated by the dopaminergic system. Brain Res 873:181-187.

Nambu T, Sakurai T, Mizukami K, Hosoya Y, Yanagisawa M, Goto K (1999) Distribution of orexin neurons in the adult rat brain. Brain Res 827:243-260

Nofzinger EA, Buysse DJ, Germain A, Price JC, Miewald JM, Kupfer DJ (2004) Functional neuroimaging evidence for hyperarousal in insomnia. Am J Psychiatry 161:2126-2128.

Orger MB, Gahtan E, Muto A, Page-McCaw P, Smear MC, Baier H (2004) Behavioral screening assays in zebrafish. Methods Cell Biol 77:53-68.

Pack AI, Galante RJ, Maislin G, Cater J, Metaxas D, Lu S, Zhang L, Von Smith R, Kay T, Lian J, Svenson K, Peters LL (2006) A novel method for high throughput phenotyping of sleep in mice. Physiol Genomics, in press.

Peyron C, Tighe DK, van den Pol AN, de Lecea L, Heller HC, Sutcliffe JG, Kilduff TS (1998) Neurons containing hypocretin (orexin) project to multiple neuronal systems. J Neurosci 18:9996-10015.

Peyron C, Faraco J, Rogers W, Ripley B, Overeem S, Charnay Y, Nevsimalova S, Aldrich M, Reynolds D, Albin R, Li R, Hungs M, Pedrazzoli M, Padigaru M, Kucherlapati M, Fan J, Maki R, Lammers GJ, Bouras C, Kucherlapati R, Nishino S, Mignot E (2000) A mutation in a case of early onset narcolepsy and a generalized absence of hypocretin peptides in human narcoleptic brains. Nat Med 6:991-997.

Piper DC, Upton N, Smith MI, Hunter AJ (2000) The novel brain neuropeptide, orexin-A, modulates the sleep-wake cycle of rats. Eur J Neurosci 12:726-730.

Reichert H, Wullimann MF, Rupp B (1996) Neuroanatomy of the zebrafish brain: a topological atlas. Basel: Birkhauser.

Sakurai T, Amemiya A, Ishii M, Matsuzaki I, Chemelli RM, Tanaka H, Williams SC, Richardson JA, Kozlowski GP, Wilson S, Arch JR, Buckingham RE, Haynes AC, Carr SA, Annan RS, McNulty DE, Liu WS, Terrett JA, Elshourbagy NA, Bergsma DJ, Yanagisawa M (1998) Orexins and orexin receptors: a family of hypothalamic neuropeptides and $\mathrm{G}$ protein-coupled receptors that regulate feeding behavior. Cell 92:573-585.

Saper CB, Cano G, Scammell TE (2005) Homeostatic, circadian, and emotional regulation of sleep. J Comp Neurol 493:92-98.

Shaw PJ, Franken P (2003) Perchance to dream: solving the mystery of sleep through genetic analysis. J Neurobiol 54:179-202.

Shaw PJ, Cirelli C, Greenspan RJ, Tononi G (2000) Correlates of sleep and waking in Drosophila melanogaster. Science 287:1834-1837.

Siegel JM (2004) Hypocretin (orexin): role in normal behavior and neuropathology. Annu Rev Psychol 55:125-148.

Siegel JM (2005) Clues to the functions of mammalian sleep. Nature 437:1264-1271.

Szekely M, Petervari E, Balasko M, Hernadi I, Uzsoki B (2002) Effects of orexins on energy balance and thermoregulation. Regul Pept 104:47-53.

Thermes V, Grabher C, Ristoratore F, Bourrat F, Choulika A, Wittbrodt J, Joly JS (2002) I-SceI meganuclease mediates highly efficient transgenesis in fish. Mech Dev 118:91-98.

Thummel R, Burket CT, Brewer JL, Sarras Jr MP, Li L, Perry M, McDermott JP, Sauer B, Hyde DR, Godwin AR (2005) Cre-mediated site-specific recombination in zebrafish embryos. Dev Dyn 233:1366-1377.

van den Pol AN (1999) Hypothalamic hypocretin (orexin): robust innervation of the spinal cord. J Neurosci 19:3171-3182. 
Willie JT, Chemelli RM, Sinton CM, Tokita S, Williams SC, Kisanuki YY, Marcus JN, Lee C, Elmquist JK, Kohlmeier KA, Leonard CS, Richardson JA, Hammer RE, Yanagisawa M (2003) Distinct narcolepsy syndromes in Orexin receptor-2 and Orexin null mice: molecular genetic dissection of non-REM and REM sleep regulatory processes. Neuron 38:715-730.

Yamanaka A, Sakurai T, Katsumoto T, Yanagisawa M, Goto K (1999) Chronic intracerebroventricular administration of orexin-A to rats increases food intake in daytime, but has no effect on body weight. Brain Res $849: 248-252$

Yamanaka A, Tsujino N, Funahashi H, Honda K, Guan JL, Wang QP, Tominaga M, Goto K, Shioda S, Sakurai T (2002) Orexins activate histaminergic neurons via the orexin 2 receptor. Biochem Biophys Res Commun 290:1237-1245.

Yamanaka A, Beuckmann CT, Willie JT, Hara J, Tsujino N, Mieda M, Tominaga M, Yagami K, Sugiyama F, Goto K, Yanagisawa M, Sakurai T (2003)
Hypothalamic orexin neurons regulate arousal according to energy balance in mice. Neuron 38:701-713.

Yoshida K, McCormack S, Espana RA, Crocker A, Scammell TE (2006) Afferents to the orexin neurons of the rat brain. J Comp Neurol 494:845-861.

Zeitzer JM, Nishino S, Mignot E (2006) The neurobiology of hypocretins (orexins), narcolepsy and related therapeutic interventions. Trends Pharmacol Sci 27:368-374.

Zhang S, Zeitzer JM, Yoshida Y, Wisor JP, Nishino S, Edgar DM, Mignot E (2004) Lesions of the suprachiasmatic nucleus eliminate the daily rhythm of hypocretin-1 release. Sleep 27:619-627.

Zhdanova IV, Wang SY, Leclair OU, Danilova NP (2001) Melatonin promotes sleep-like state in zebrafish. Brain Res 903:263-268.

Zon LI, Peterson RT (2005) In vivo drug discovery in the zebrafish. Nat Rev Drug Discov 4:35-44. 